\title{
LA COMPETENCIA EXCLUSIVA DE LAS COMUNIDADES AUTÓNOMAS EN MATERIA DE CONSULTAS POPULARES
}

\author{
NICOLÁS PÉREZ SOLA \\ Profesor Titular de Derecho Constitucional \\ Universidad de Jaén
}

\author{
SUMARIO \\ I. Introducción. \\ II. Los referéndum municipales. \\ III. El referéndum en el ámbito autonómico. \\ IV. Las perspectivas que abren las nuevas \\ regulaciones estatutarias.
}

\section{INTRODUCCIÓN}

Entre las aportaciones originales de los nuevos Estatutos de Autonomía de Cataluña y Andalucía se encuentra la atribución de la competencia exclusiva para la convocatoria y celebración de consultas populares a dichas Comunidades. Así el Consejo de Gobierno de Cataluña aprobó el pasado 31 de marzo de 2009 el proyecto de ley de consultas populares por vía de referéndum de Cataluña para su tramitación parlamentaria. Es por ello que queremos llevar a cabo un breve análisis respecto de algunas cuestiones que se derivan de esta atribución competencial. Además las recientes sentencias del Tribunal Constitucional (SSTC 247/2007 y 103/2008) constituyen un material imprescindible para reflexionar sobre la viabilidad de las consultas populares en el ámbito autonómico.

Aun cuando pudiéramos pensar que estamos ante una cuestión menor, dada la relativamente escasa relevancia de la misma en el conjunto de la diversa problemática que suscita el presente momento del Estado autonómico, no es menos cierto que quizá fuese saludable suscitar un debate académico sobre la misma. De un lado, porque las aportaciones doctrinales en la mate- 
ria no han sido muy profusas en los últimos tiempos ${ }^{1}$ y secundado por un manifiesto desinterés del legislador sobre la misma. Únicamente cuando el ejecutivo se ha visto precisado, ha reparado en la necesidad de hacer una breve incursión en este instrumento de participación política, como sucedió con la norma de convocatoria del referéndum sobre el Tratado por el que se establecía una Constitución para Europa ${ }^{2}$. De otra parte, ni el Consejo de Estado ni tampoco el Alto Tribunal han generado, a nuestro entender, unas aportaciones sólidas sobre el encaje de los instrumentos de participación directa de los ciudadanos en el ámbito autonómico, ni tan siquiera sobre su conceptualización y caracterización frente a otras fórmulas participativas cuando se ha pronunciado sobre la convocatoria de consulta popular del Lehendakari resuelta en la STC 103/20083.

En todo caso, no es intención de quien formula este breve análisis llevar a cabo un comentario de la STC 103/2008, sino de propiciar que a la luz de las recientes reformas estatutarias y la recepción de nuevos instrumentos participativos, se pueda generar un espacio de debate y reflexión sobre la aparente «revitalización" de las fórmulas de participación directa en el ámbito autonómico.

El punto de partida por tanto lo constituyen las recientes reformas estatutarias en materia de consultas popular. A tenor de los nuevos Estatutos de Autonomía de Cataluña y Andalucía podría tener lugar el desarrollo de la legislación relativa al establecimiento del régimen jurídico, las modalidades, el procedimiento, la realización y la convocatoria por ella misma o por los entes locales en el ámbito de sus competencias de encuestas, audiencias públicas, foros de participación y cualquier instrumento de consulta popular. No obstante, cabe decir que los términos en que se recoge esta competencia en ambos Estatutos no es idéntica, toda vez que en el de Andalucía se especifica "Con la excepción del referéndum" (art. 78), frente al de Cataluña en el que se indica "Con la excepción de lo previsto en el art. 149.1.23 CE" (art. 122). Todo ello sin perjuicio del derecho reconocido en ambos Estatutos a "promover la convocatoria de consultas populares por la Junta de Andalucía o por

1 Hasta donde alcanzamos a conocer LASAGABASTER HERRARTE, I., Consulta o referéndum. La necesidad de una nueva reflexión jurídica sobre la idea de democracia, Lete, Bilbao 2008; RODRÍGUEZ, A., "Consultas populares", en Reformas estatutarias y distribución de competencias BALAGUER CALLEJÓN, F. (Dir.) Consejería de Justicia y Administración Pública, Sevilla 2007; IBÁÑEZ MACÍAS, A., El referéndum local en España: régimen jurídico, Universidad de Cádiz, 2005; LÓPEZ GONZÁLEZ, J.L., El referéndum en el sistema español de participación politica, Universidad Politécnica de Valencia, Valencia, 2005; AGUIAR DE LUQUE, L., "Democracia directa e instituciones de democracia directa en el ordenamiento constitucional español" en TRUJILLO, G.; LÓPEZ GUERRA, L.; GONZÁLEZ TREVIJANO, P. (Dirs.): La experiencia constitucional (1978-2000) CEPC, Madrid 2000.

2 En efecto, el instrumento de convocatoria fue en este caso la Ley Orgánica 17/2003 de medidas para la celebración simultánea de las elecciones al Parlamento Europeo y del Referéndum sobre el Proyecto de Constitución Europea.

3 Como es conocido el 27 de junio de 2008 el Pleno del Parlamento Vasco aprobó la Ley 9/2008, de convocatoria y regulación de una consulta popular al objeto de recabar la opinión ciudadana en la Comunidad Autónoma del País Vasco sobre la apertura de un proceso de negociación para alcanzar la paz y la normalización política. 
los Ayuntamientos" (art. 30.1.c) o por la Generalitat o los Ayuntamientos «en materia de las competencias respectivas, en la forma y las condiciones que las leyes establecen" (art. 29).

Aunque otras referencias aparezcan en los Estatutos de Autonomía reformados y tengan aparente menor alcance, deben ser reseñadas también, ya que se atribuyen competencias de desarrollo legislativo y ejecución sobre el sistema de consultas populares en los términos de los artículos 92 y 149.1.32 $\mathrm{CE}$ a las Islas Baleares (art. 31.10) y con referencias a uno u otro precepto en los Estatutos de Castilla y León (art. 71.1.15) y Aragón (71.27). Con todo, no conviene olvidar como sin una justificación aparente ya en el pasado algunos Estatutos de Autonomía habían recogido su competencia de desarrollo legislativo y ejecución sobre el sistema de consultas populares en el ámbito de la Comunidad Autónoma al amparo entendemos del art. 148.1 CE ${ }^{4}$. Nos referimos en concreto a los Estatutos de Asturias (art. 11), Canarias (art. 32), Extremadura (art. 8 ), Murcia (art. 11), La Rioja (art. 9) e Islas Baleares con una redacción ahora modificada.

Por lo que aquí interesa, nos hemos de ocupar también de los derechos reconocidos estatutariamente, baste recordar que se ha reconocido el derecho de los ciudadanos a promover la convocatoria de consultas populares en los Estatutos de Cataluña (art. 29.6), Andalucía (art. 30), Islas Baleares (art. 15, c) y Castilla y León (art. 11.5). Son estas aportaciones estatutarias las que nos invitan a reflexionar sobre la oportunidad de plantear el debate en torno a la proyección autonómica del referéndum y para determinar en que medida se trataría de una serie de derechos de participación derivados de las demandas del estado democrático, que legitimaría actuaciones de las instituciones autonómicas, con el consiguiente incremento de las formas de participación política en el ámbito de las Comunidades Autónomas.

Constituye sin duda una novedad que los Estatutos de Cataluña y Andalucía contengan un título reservado a la proclamación, reconocimiento y, en el caso del Estatuto Catalán, garantía del ejercicio de una serie de derechos. Aun cuando desde su formulación no resulten coincidentes, ya que en el Estatuto de Autonomía de Andalucía se recogen bajo la denominación de derechos sociales, deberes y políticas públicas y en el enunciado del Estatuto Catalán se trate de derechos, deberes y principios rectores, es claro que admiten una reflexión común en torno a la eficacia de su plasmación estatutaria. Quizá la nota más destacada inicialmente sea que el reconocimiento de derechos se hace a favor de las personas con vecindad administrativa en Andalucía (art. 12) y esto debe ser sobradamente destacado, frente al reconocimiento de derechos a los ciudadanos que podrá extenderse al resto de las personas en el Estatuto catalán (art. 15).

4 En el Dictamen del Consejo de Estado de 21 de junio de 2001 sobre el proyecto de Real Decreto regulador del procedimiento de autorización por el Gobierno de la nación de las consultas populares se abogaba por «insertar la materia en el art. 149.1.18 CE en relación con las bases del régimen local: de esa manera resulta indiscutible la competencia del conjunto de las Comunidades Autónomas para ordenar las consultas populares municipales". 
Frente a estos nuevos contenidos estatutarios la dificultad ante la que nos encontramos no es menor, ya que convergen en este análisis la concreción de los "derechos estatutarios" de participación política de un lado y la distribución competencial en diversas materias de otro. Hemos pues de reflexionar sobre el alcance de la competencia exclusiva del Estado para la determinación del estatuto jurídico de los derechos fundamentales de los ciudadanos al objeto de concretar el alcance de estos derechos estatutarios. Es cierto que en una lectura inicial de la Carta Magna encontramos un ámbito de competencia exclusiva estatal referenciado expresamente y, quizá como cláusula de cierre del sistema, en el propio enunciado del artículo 149.1.1 CE, en tanto que competencia estatal para establecer las condiciones básicas que garanticen la igualdad entre "los españoles".

En concreto y ante la indeterminación del estatuyente, que en ningún caso ha adjetivado como fundamentales los derechos reconocidos en los nuevos Estatutos, se impone una primera lectura literal de los títulos y capítulos de estas normas, en orden a clarificar, en la medida en que esto sea posible, la naturaleza de los derechos proclamados estatutariamente como tales. Parece evidente que se ha evitado cualquier alusión a la fundamentalidad de los mismos para no incurrir en vicio de inconstitucionalidad. De otra parte, puede sorprender el nivel de eficacia de dichas proclamaciones en la medida en la que en las normas estatutarias se acompaña la invocación a un futuro desarrollo legislativo parlamentario posterior para su concreción.

Un breve repaso al estado actual de la jurisprudencia constitucional puede ilustrar esta problemática a partir de la resolución de los recursos planteados contra el Estatuto de Valencia. Recordemos brevemente que pese a la impugnación ante el Tribunal Constitucional por la Comunidad Autónoma de Aragón de la asunción de competencias recogida en la reforma del Estatuto de Valencia sobre los sobrantes de cuencas excedentarias ${ }^{5}$, ha sido ésta declarada constitucional por el Alto Tribunal (STC 247/207) ${ }^{6}$. En el mismo sentido con posterioridad el Tribunal también ha desestimado el recurso planteado por la Comunidad Autónoma de Castilla-León contra el mismo precepto (STC 249/2007). Nos interesan estas resoluciones porque el Alto Tribunal, aporta la más reciente interpretación constitucional sobre el Estado Autonómico y aborda la oportunidad de incluir la proclamación de derechos en los nuevos Estatutos en estas sentencias. En concreto, en este caso se trata del derecho a "disfrutar de aguas de calidad en cantidad suficiente y acceder a la redistribución de los caudales que provengan de cuencas excedentarias". En la STC 247/2007, el Tribunal avanza que «nada impide que el Estatuto de Au-

5 «Se garantiza el derecho de los valencianos y valencianas a disponer del abastecimiento suficiente de agua de calidad. Igualmente se reconoce el derecho de redistribución de los sobrantes de cuencas excedentarias atendiendo a criterios de sostenibilidad de acuerdo con la constitución y la legislación estatal" (art. 17.1 EAV).

6 «el derecho al abastecimiento de agua regulado en el art. 17.1 EACV constituye un objetivo marcado a los poderes públicos valencianos, lo que sitúa al precepto estatutario recurrido en el ámbito del Estado social y democrático de Derecho previsto en la Constitución (art. 1.1)". 
tonomía, en cuanto norma institucional básica de la Comunidad Autónoma, al atribuir las competencias que han de ejercer los poderes públicos autonómicos, les impongan, de modo directo, criterios o directrices para su ejercicio o que lo hagan, de modo indirecto, mediante la formalización de enunciados o declaraciones de derechos a favor de los particulares", pero matiza el alcance a través de una doble concreción. De un lado, es preciso hacer hincapié en que se trata de "mandatos" a los poderes públicos autonómicos que "deberán estar conectados con una materia atribuida como competencia por el Estatuto" ${ }^{7}$. De otra parte, los mandatos contenidos en el Estatuto precisarán de desarrollo legislativo autonómico "de la competencia normativa que le es propia" para conseguir "plena eficacia". Estas matizaciones de nuestro Alto Tribunal creemos que permitirían desarrollos estatutarios de los derechos de participación política directa previstos en ellos sobre materias de su competencia.

Varias son por tanto las cuestiones que deben ser brevemente analizadas: el régimen jurídico del referéndum, las nuevas regulaciones estatutarias y las posibles disfunciones que se puedan derivar de ellos.

\section{I.1. El Derecho de participación política directa}

El punto de partida debe ser la concepción constitucional dual del derecho fundamental a la participación política (art. $23 \mathrm{CE}$ ), que está manifiestamente descompensada en favor de la representación, lo que muestra la insuficiencia real de la participación directa en nuestro sistema jurídico, situándonos ante la verdadera dimensión del problema: la escasa virtualidad de este derecho fundamental frente a la excesiva formalización de la representación política y los órganos de representación de los ciudadanos. Desde la perspectiva del derecho afectado cabe decir que si bien estamos ante un derecho fundamental, sólo parcialmente ha sido desarrollado en la Ley Orgánica de Modalidades de Referéndum (en adelante LOMR), por lo que debemos colegir que de la incomplitud de esta norma, se deriva una percepción restrictiva del ejercicio de un derecho fundamental, que conectado con el principio democrático debiera ser objeto de una interpretación pro actione ${ }^{8}$. Evidentemente ni el desarrollo legislativo del artículo 92 ni del artículo 149.1.32 CE agotan la regulación de las manifestaciones directas de este de-

7 El alcance de esta afirmación ha sido destacado por Canosa Usera ya que el Tribunal Constitucional hace hincapié en la consideración como simple mandato y no como derecho subjetivo del que sería titular el ciudadano. CANOSA USERA, R., "Preparando una mutación constitucional. Comentario a la STC $247 / 2007$ de 13 de diciembre", Teoría y Realidad Constitucional, núm 22, pág. 582.

8 Esta percepción restrictiva se suscribe por el Consejo de Estado en el Dictamen núm. $1.119 / 2008$ al afirmar que "aún si se admitiera que la ley puede ampliar los casos de participación directa, los supuestos habrían de ser, en todo caso, excepcionales en un régimen de democracia representativa como el instaurado por nuestra Constitución". 
recho fundamental. De otra parte, se recoge un afán restrictivo respecto de esta formula de participación directa en la propia jurisprudencia constitucional ya señalada por Aguiar', como se acredita en las SSTC 63/1987 y 119/1995. En cierta manera se complementa la línea jurisprudencial de exclusión de las manifestaciones directas de este derecho fundamental en las SSTC 212/1993 189/1993, 23/1984 y 80/1994. La estricta concepción de los instrumentos de participación directa de los ciudadanos en los asuntos públicos se contiene también en los Dictámenes del Consejo de Estado y es asumida sin suficiente argumentación a nuestro entender por el propio Tribunal Constitucional (STC 103/2008). En esta concepción que preside la legislación y jurisprudencia brevemente reseñada encuentra muy difícil acomodo el reconocimiento estatutario de competencias en orden al desarrollo y ejecución de consultas populares, aun cuando expresamente se señalen los artículos $92 \mathrm{y}$ 149.1.32 CE para enmarcar esta competencia.

En efecto, el Tribunal Constitucional ha concretado el alcance del referéndum al definirlo como "un instrumento de participación directa de los ciudadanos en los asuntos públicos (...) para el ejercicio del derecho fundamental" (art. 23.1 CE). Ahora bien, el referéndum así "no es cauce para la instrumentación de cualquier derecho de participación, sino específicamente para el ejercicio del derecho de participación política" y se define como una "forma de democracia directa y no una mera manifestación del fenómeno participativo". Por tanto, no cabe identificar el referéndum con otras manifestaciones participativas reconocidas constitucionalmente "en las que se articulan voluntades particulares o colectivas, pero no generales (...) no imputables al cuerpo electoral". Así el referéndum es definido como "una especie del género consulta popular con la que no se recaba la opinión de cualquier colectivo sobre cualesquiera asuntos de interés público a través de cualesquiera procedimientos, sino aquella consulta cuyo objeto se refiere estrictamente al parecer del cuerpo electoral". En suma para el Tribunal Constitucional es determinante para definir una consulta como referéndum que su convocatoria requiere entonces de una autorización reservada al Estado, y ha de atenderse a la identidad del sujeto consultado, de manera que siempre que éste sea el cuerpo electoral, cuya vía de manifestación propia es la de los distintos procedimientos electorales con sus correspondientes garantías, sólo entonces estaríamos ante una consulta referendaria (STC 103/2008).

El Tribunal Constitucional ha hecho especial hincapié en el derecho a la participación política directa a través del referéndum indicando que "para participar en los asuntos concretos se requiere un especial llamamiento o una especial competencia si se trata de órganos públicos, o una especial legitimación si se trata de entidades o sujetos de derecho privado, que la ley puede

9 Este autor se hace eco de como el Tribunal Constitucional no "ha seguido un criterio tan restrictivo como el empleado para delimitar los contenidos del derecho de participación directa, cuando ha analizado el derecho a participar a través de representantes" AGUIAR DE LUQUE, L., GONZÁLEZ AYALA, M. D., "Comentario al Artículo 23 CE" en Comentario a las Leyes Políticas, EDERSA 1997, pág. 656. 
en tal caso, organizar ${ }^{10}$. Es quizá aquí donde se expresa con mayor énfasis por el Alto Tribunal la pertinencia de ajustar el ejercicio del derecho a su previa configuración por la norma de desarrollo, "es lo cierto - indicaba el Tribunal- que ese derecho constitucional que a los ciudadanos se atribuye para participar en los asuntos públicos, ha de ejercitarse - obvio es decirloadecuadamente a las previsiones que la normativa en cada caso establezca, previsiones que en lo que aquí y ahora importa están incluidas en la Ley orgánica " ${ }^{11}$.

Hemos de reparar pues en las limitaciones que plantea el desarrollo legislativo del artículo $23 \mathrm{CE}$ ya que no estamos ante cuestiones reguladas en la Ley Orgánica de Régimen Electoral General (en adelante LOREG), ni tampoco en la Ley Orgánica de Iniciativa Legislativa Popular. Ahora bien, la Constitución recoge ocho tipos diferentes de consultas directas por lo que la LOMR debería haber contemplado la regulación de todas y cada una de ellas y no haberse centrado prácticamente en los referéndum autonómicos para dar una salida al proceso de generalizado acceso a la autonomía. Por tanto, una lectura de la LOMR no arroja excesiva luz sobre esta cuestión, aunque se haya argumentado, quizá con excesiva contundencia, por el Consejo de Estado en el Dictamen núm. 1.119/2008 que "Todos los posibles referéndum autonómicos, incluidos los consultivos, están regulados por la Ley orgánica 2/1980 (...), y en su caso, por diversas normas de los Estatutos de Autonomía", para apostillar que "no son admisibles otros referendos que los previstos en la Constitución, la cual encomienda su autorización al Estado y reserva su regulación a la ley orgánica" (art. $92 \mathrm{CE}$ ).

Compartimos con Aguiar el carácter no cerrado de la formulación contenida en el art. 92 CE que llevó a este autor a señalar que este precepto «en ningún punto consagra de modo explícito que el ámbito de estas consultas populares debe ser todo el territorio nacional". Somos por tanto partidarios de un entendimiento amplio de este procedimiento ya que "las instituciones de participación directa cuentan en el texto constitucional con una vis expansiva fruto del mandato de maximización de la participación contenida en el art. 9.2 o del reconocimiento de la participación directa en los asuntos públicos como un derecho fundamental que realiza el art. $23 \mathrm{CE}^{12}$.

También se ha apuntado para la correcta definición de las consultas populares "el criterio de la inclusión" que posibilitaría su consideración únicamente para "las consultas constitucionalmente establecidas", si bien se debería completar con "la finalidad de la consulta, de modo que habrá que incluir también aquéllas, aunque no estén previstas en la CE, en las que se llame a participar al pueblo ejerciendo un poder político, como titular de la

10 STC 51/1984

11 AATC de 16 de enero y 18 de septiembre de 1985, correspondientes a los recursos promovidos contra el acuerdo de la Mesa del Congreso de los Diputados inadmitiendo a trámite proposiciones de ley de iniciativa popular sobre pensiones de jubilación para administradores familiares.

12 AGUIAR DE LUQUE, L., en La experiencia..., Op. cit., pág. 87. 
soberanía" ${ }^{13}$. Ha habido en efecto una necesidad aún no satisfecha por el Tribunal Constitucional en orden a determinar si la participación en un referéndum local "supone o no ejercicio de ese derecho" de participación política del artículo $23 \mathrm{CE}^{14}$. Por ello, ya señalamos hace tiempo la necesidad de una reforma de la LOMR que diera cabida a las consultas autonómicas ${ }^{15}$.

A nuestro entender, es legítimo discutir respecto del alcance de la competencia exclusiva autonómica sobre la autorización de las consultas populares como instrumentos de participación directa en asuntos públicos, pero no respecto a la posibilidad de su regulación y convocatoria. Un desarrollo lógico del principio democrático y de la interpretación favorable de la eficacia de los derechos fundamentales avalaría este entendimiento. Recordemos como señaló el Tribunal Constitucional que «las condiciones básicas que garantizan la igualdad, por definición, no pueden consistir en un régimen jurídico acabado y completo de los derechos y deberes constitucionales afectados. La regulación de esas condiciones básicas sí corresponde por entero y en exclusiva al Estado, pero con tal normación, como es evidente, no se determina ni se agota su entero régimen jurídico" (STC 61/1997). En este sentido Soloza$\mathrm{bal}^{16}$ ha reiterado recientemente que los "derechos fundamentales no se encuentran reservados al legislador estatal".

A partir de aquí encontramos al menos dos líneas argumentales que pueden propiciar el desarrollo complementario del derecho a la participación política directa en las Comunidades Autónomas atendiendo, tanto a la jurisprudencia constitucional relativa al derecho de asociación, como a la regulación de la iniciativa legislativa popular autonómica.

En el ámbito del desarrollo de los derechos fundamentales se debe recordar como hay margen para la regulación autonómica de éstos (STC 173/1998 y 135/2006 relativas a la Ley vasca y catalana respectivamente de asociaciones). Algún paralelismo se puede seguir de la jurisprudencia constitucional sobre el derecho de asociación, pues el Alto Tribunal ha señalado que "cuando se trata de competencias que se ejercen en relación con una materia cuyo núcleo lo constituye el derecho fundamental (...) sujeto a la reserva de Ley Orgánica, del art. 81.1 CE debe considerarse reservado a la ley orgánica ex art. 81.1 CE la regulación de los elementos esenciales de la definición del derecho de asociación, o, en otras palabras, la delimitación de "los aspectos esenciales del contenido del derecho" en lo tocante a la titularidad

13 En efecto quien apunta que estas consultas "al pesar sobre ellos la reserva competencial del art. 149.1.32, podrían entenderse incluidos en el catálogo de las consultas que deben considerarse ejercicio de este derecho". RODRÍGUEZ, A., Op. cit., pág 881.

14 Ibídem, pág. 884.

15 PÉREZ SOLA, N., La regulación constitucional del referéndum, Universidad de Jaén, 1994.

16 En este sentido Solozabal apunta con buen criterio que "no habría venido mal una referencia explícita a los límites que tiene esta encomienda de promoción de las consultas populares por parte de la Generalitat". SOLOZABAL, J.J., "Algunas consideraciones sobre las reformas estatutarias", Teoría y Realidad constitucional, núm. 22, pág. 332. 
de las facultades elementales que lo integran en sus varias vertientes" ${ }^{17}$. Por tanto, no quedaría agotado el margen de regulación y dejaría espacio para una regulación de desarrollo autonómica ${ }^{18}$. Hemos de reiterar también a mayor abundamiento la conocida doctrina de nuestro Alto Tribunal sobre la "exigencia de que los límites de los derechos fundamentales hayan de ser interpretados con criterios restrictivos y en el sentido más favorable a la eficacia y a la esencia de tales derechos" (SSTC 159/1986 y 254/1988).

De otro lado, la regulación autonómica de la iniciativa legislativa popular, que incide directamente en el ejercicio del derecho a la participación política directa, no ha suscitado nunca sospecha de inconstitucionalidad. Al igual que ha sucedido con la iniciativa legislativa popular autonómica, cabe entender que "podría distinguirse la regulación del derecho fundamental de participación en las consultas populares, en cuanto manifestación de una forma de democracia directa, es decir, los aspectos esenciales del derecho encuadrados en el ámbito de la reserva a la ley orgánica, mientras que no lo estaría el régimen jurídico de las consultas populares autonómicas, cuya regulación corresponde al legislador ordinario, y en este caso, lógicamente, al autonómico" ${ }^{19}$. Sería entonces admisible la realización de un paralelismo con la iniciativa legislativa popular, toda vez que si «las Comunidades Autónomas no precisan una norma competencial que las habilite para regular la iniciativa legislativa popular en el ámbito autonómico ni están obligados a hacerlo", igualmente podría darse traslado al ámbito del referéndum, lo que da pie a Lasagabaster para afirmar "que la regulación de las consultas populares queda abierta a la legislación autonómica como un componente insito de la democracia que no precisa reconocimiento expreso" ${ }^{20}$.

Pero si ampliamos el objeto de análisis a los Estatutos de aquellas Comunidades Autónomas que no han asumido aún esta competencia y constatamos la presencia en alguna de ellas de la normativa autonómica específica sobre consultas populares locales tendremos que admitir, al menos en el supuesto de Navarra, que ha sido la competencia en administración local de la Comunidad Autónoma la que ha fundamentado la legislación en esta materia, pese a no contar con previsión estatutaria alguna relativa a consultas populares.

17 Frente a esta argumentación el Tribunal no deja de afirmar que "la calificación de esta competencia autonómica como exclusiva no puede interpretarse como un total desapoderamiento del Estado".

18 "aun admitiendo que entre la regulación del derecho de asociación y la del régimen jurídico de las asociaciones existe una zona de difícil delimitación y que, en consecuencia, en algunos casos la inclusión en una u otra categoría dependerá del grado más o menos intenso de proximidad con uno u otro ámbito, este criterio ha de ser el punto de partida inexcusable para delimitar lo reservado a la Ley Orgánica y lo que corresponde a los títulos competenciales relacionados con la materia de asociaciones y muy especialmente lo que corresponde al legislador ordinario, sea estatal o autonómico, con competencias en estas materias" (STC 135/2006).

19 En este sentido se ha manifestado LASAGABASTER. LASGABASTER, I., Op. cit., pág. 92 y ss.

20 Ibídem, pág. 92-93. 


\section{I.2. REFERÉNDUM VERSUS CONSULTA POPULAR}

La discusión doctrinal que se está desarrollando al tiempo de escribir estas líneas gira en torno a si existe una relación género especie entre consultas populares y referéndum en el sentido de entender que los Estatutos Catalán y Andaluz posibilitarían otras formas de participación directa de los ciudadanos más allá del referéndum, que sí estaría sujeto al imperativo de su autorización estatal de conformidad con la Constitución y la LOMR. En todo caso, se debe recordar como el desarrollo estatutario pende de la resolución por parte del Tribunal Constitucional de los recursos de inconstitucionalidad presentados por el Defensor del Pueblo y el Partido Popular relativos al Estatuto de Cataluña.

Es cierto que la doctrina primero y más tarde el propio Tribunal Constitucional han reparado en la distinción entre referéndum y consulta popular, pero no creemos que de esta distinción se puedan seguir conclusiones definitivas $^{21}$. La literalidad de los términos puede conllevar simplificaciones excesivas, pues se trata de una cuestión insuficientemente fundamentada y sobre la que no compartimos la existencia de una diferencia conceptual relevante entre estas formulaciones gramaticales contenidas en la Norma Fundamental como en la LOMR, Ley de Bases de Régimen Local (en adelante LBRL) y en los Estatutos de Autonomía y leyes autonómicas que recogen la figura de las consultas populares locales. No pretendemos aquí formular una construcción conceptual del referéndum y de las consultas populares, cuanto de determinar si tras estas expresiones se oculta una ratio última que justifique unas consecuencias jurídicas diversas y, permita impulsar bien la participación ciudadana en el ámbito autonómico, bien implique una fractura constitucional su reconocimiento estatutario.

Llegados a este punto hemos de recordar que la aparente diferenciación entre ambas figuras es evidente que ha recorrido un camino tortuoso y recobrado actualidad al hilo del proceso de propuesta de referéndum en el País Vasco. Pero no podemos compartir lo que a nuestro juicio solo puede constituir un ardid para distraer nuestro centro de atención, ya que estamos ante una distinción quizá artificiosa entre referéndum y consulta popular ${ }^{22}$. Ciertamente esta distinción podría encontrar su justificación en diversos antecedentes como el Estatuto Municipal de 1924 y la Ley Municipal de Cataluña de 1933; así tiene acogida en los términos exactos reiterados en la LBRL. Esta

21 La participación directa que en los asuntos públicos ha de corresponder a los ciudadanos es la que se alcanza a través de las consultas populares previstas en la propia Constitución" (STS 63/1987).

22 A. Rodríguez apunta para la correcta definición de las consultas populares de un lado "el criterio de la inclusión" que posibilitaría su consideración únicamente para "las consultas constitucionalmente establecidas" si bien se debería completar con "la finalidad de la consulta, de modo que habrá que incluir también aquéllas, aunque no estén previstas en la CE, en las que se llame a participar al pueblo ejerciendo un poder político, como titular de la soberanía". RODRÍGUEZ, A., Op. cit., pág. 881. 
indefinición, incluso confusión entre referéndum y consulta aparece también en el reglamento de participación del Ayuntamiento de Barcelona de $1986^{23}$. Pero de aquí a trazar una separación drástica entre ambas parece, al menos, no suficientemente fundamentada ni en los antecedentes que obran en el citado Dictamen del Consejo de Estado ${ }^{24}$ ni en el propio texto de la Sentencia del Alto Tribunal (STC 103/2008). Desde esta última instancia, tan solo se abordó en aquella resolución la diferencia a título nominal entre ambas, sin llevar a cabo un análisis de las consecuencias que se derivarían de la misma. En todo caso, por cuanto respecta al alcance, contenido y límites del derecho a la participación política directa en asuntos públicos, nada habría que objetar más allá del mero nominalismo, a las consultas populares locales, ni tampoco a las autonómicas, siempre que se respetasen los parámetros ya indicados. No parece necesario desarrollar nuevamente el argumentario circular ya esbozado a la luz de la STC 103/2008 que reitera jurisprudencia anterior. Contamos con la propia jurisprudencia del Tribunal Constitucional para precisar lo que no es contenido constitucionalmente reconocido del derecho de participación política directa en los asuntos públicos, a partir de ahí, hemos de entender que las "consultas populares" acogidas estatutariamente, no se refieren a esas otras formas de participación que encuentran su fundamentación amplia en la propia Constitución (art. 9.2), sino muy al contrario, constituirían manifestaciones claras e indubitables del ejercicio del derecho fundamental a la participación política.

Por tanto queremos centrarnos en la asunción competencial estatutaria sobre la regulación del ejercicio del derecho de participación directa de los ciudadanos de la Comunidad Autónoma y es aquí donde la literalidad de los términos recogidos en los Estatutos catalán y andaluz no se agotan con una interpretación "textual", sino que admiten margen para otras interpretaciones no excluyentes ${ }^{25}$. Es aquí donde se hace notar, a nuestro entender, la falta de una construcción doctrinal suficiente que ha evidenciado el propio Tribunal Constitucional en la STC 103/2008. La diversidad de cuestiones sin respuestas en esta Sentencia nos sitúan ante la indeterminación de si ¿Sólo pueden ser

23 «El Ayuntamiento y cada uno de sus Distritos podrán consultar la opinión de los ciudadanos en materia de su competencia a través del referéndum y la consulta ciudadana". Aunque como señalaba Ibáñez Macías la comprensión de todo el censo y la previsión de que se llevara a cabo en las urnas hacia pensar realmente en un referéndum. IBÁÑEZ MACÍAS, A., Op. cit., pág. 129.

24 En este Dictamen se indica a propósito de la iniciativa de consulta del Lehendakari que "no se trata, pues de una consulta no calificable de referéndum como lo sería una consulta limitada a tratar de conocer la opinión de la ciudadanía (...) por medios que no impliquen el ejercicio del derecho de sufragio". Para caracterizar a continuación que "Las recientes reformas de los Estatutos han regulado también esta materia (...) en los preceptos dedicados a la enunciación de competencias, en algunos casos, se enumeran instrumentos de consulta dirigidos a la expresión de una opinión popular y no de un acto de voluntad con excepción de lo previsto en el art. 149.1.32 CE (Cataluña) o del referéndum (Andalucía) o de ambos (Aragón)».

25 Como ha señalado Lasagabaster "la regulación puede no agotar todas las posibilidades", apuntando además "que no se haya regulado un determinado aspecto de una materia no significa que no se tenga competencia para hacerlo" LASAGABASTER, I., Op. cit., pág 81. 
considerados como referéndum los expresamente previstos en la Constitución? Por tanto únicamente sobre ellos cabría la competencia exclusiva del Estado. Ahora bien, ¿Qué sucede con las consultas populares locales? No están previstas constitucionalmente, y sin embargo, pese a su no regulación en una ley básica, si tienen cabida en nuestro sistema jurídico. ¿Por qué no entonces dar entrada a las consultas populares autonómicas? La cuestión es que el diverso tratamiento estatuario de la materia ha permitido una regulación autonómica de las consultas locales, pero la reserva del artículo 149.1.32 CE está referida a la convocatoria del mismo, no así a la regulación de la consulta por vía de referéndum. Significa esto que ¿La previsión estatutaria para su regulación tendría acomodo constitucional salvado el reconocimiento de la competencia exclusiva estatal para su convocatoria? En el mismo sentido, no cabe extraer de una norma tan insuficiente como la LOMR ninguna orientación ya que se trata de una norma que desarrolla el artículo $92 \mathrm{CE}$, pero en ningún caso concreta el alcance del artículo 149.1.32 CE más allá de las previsiones procedimentales relativas a los referéndum previstos en la Constitución.

La cuestión a discernir se circunscribiría pues al ámbito estrictamente competencial: bien para elaborar la normativa de desarrollo y de aplicación supletoria en su caso, bien para determinar la competencia relativa a su autorización. Es en este sentido en el que entendemos que salvada la competencia exclusiva del Estado para su autorización, extremo este sobre el que no albergamos duda alguna, no debería de existir obstáculo para considerar plenamente constitucional la asunción estatutaria de esta competencia, así como su desarrollo legislativo autonómico. Debemos reiterar nuestra convicción de que la asunción competencial en la materia por los Estatutos de Autonomía de Cataluña y Andalucía y su ulterior desarrollo estatutario en ningún caso cabría entenderlo como desarrollo de la normativa básica estatal, como si se ha recogido en los restantes Estatutos recientemente reformados y sobre la que inicialmente el Estado no tendría titulo competencial alguno.

Ahora bien, afirmaciones del Alto Tribunal como "la participación directa que en los asuntos públicos ha de corresponder a los ciudadanos es la que se alcanza a través de las consultas populares previstas en la propia Constitución" (STC 63/1987), que es objeto de reproducción en la STC 103/2008, cuando menos debiera ser matizada. Una interpretación literal de la misma podría condenar a la inconstitucionalidad las previsiones tanto estatutarias como las contenidas en la LBRL y las normas andaluza y navarra sobre las consultas locales. Por tanto, conviene no apresurarse a la hora de extraer consecuencias de determinadas afirmaciones del Tribunal. Consideramos que se deriva un elevado riesgo de la literalidad de algunos de los preceptos legales en presencia y, por ello, debe sopesarse la interpretación de los mismos. Si podemos convenir en el carácter incompleto de la LOMR, hemos de admitir que de dicha incomplitud no cabe deducir de forma taxativa la imposibilidad de otros instrumentos de participación directa de los ciudadanos en los asuntos públicos, una vez descartadas otras formulas participativas en 
consonancia con lo indicado por el Tribunal Constitucional. Además, la pervivencia en el tiempo sin ser cuestionadas de las fórmulas locales de consulta directa a la ciudadanía confirmarían tal afirmación. Un posterior interrogante nos surge rápidamente que debe ser disipado ¿Cuál es la correcta caracterización de la LOMR? Varias son las notas que deben ser aplicadas a aquélla. De una parte se debe despejar la incógnita sobre su fundamentación que entendemos descansa en el artículo $92 \mathrm{CE}$, pero no así en el artículo 23 CE. Por otro lado, la conexión de la LOMR con la competencia exclusiva del Estado para la autorización de los referéndum no agota todas las posibilidades interpretativas ${ }^{26}$. Toda vez que los Estatutos de Autonomía han acogido la competencia sobre consultas populares inicialmente no previstas ni en la Constitución ni en la LOMR y, no habiéndose impugnado su inconstitucionalidad, cabría pensar que "desarrollo y ejecución" de las mismas competería a las Comunidades Autónomas, sin especial sujeción a la LOMR, que sólo viene referida a los referéndum previstos en la Constitución. Quizá un análisis más profundo sobre la idoneidad de extender de forma omnicomprensiva la competencia estatal a la convocatoria de consultas populares no previstas en nuestra Magna Carta, requeriría tiempo y espacio que ya parece casi excedido en este momento. No obstante, si conviene hacer hincapié en el ámbito en el que opera el artículo 149.1.23 CE, la competencia exclusiva sobre la autorización de la convocatoria y, en ningún caso, de la regulación de los referéndum.

\section{LOS REFERÉNDUM MUNICIPALES}

La Disposición Adicional de la LOMR admite expresamente la existencia de referéndum municipales que son denominados "consultas populares locales", dejando su regulación y celebración a lo previsto en la legislación de régimen local. Por tanto, la no inclusión de esta modalidad de referéndum en la LOMR constituye un evidente incumplimiento constitucional por no respetar la reserva de Ley Orgánica que se establece en el art. 92.3 CE, al margen de que aspectos procedimentales puntuales queden a regulación de una norma ordinaria. La disparidad de encuadre de la competencia de las Comunidades Autónomas sobre consultas populares llevaría a concluir con la doctrina que dichas competencias autonómicas para su regulación se insertan en la capacidad de autoorganización de las mimas.

En efecto, la LBRL da cobertura y reconocimiento a este tipo de consultas que han de recaer sobre cuestiones especialmente relevantes para la vida vecinal, excluidas las materias referidas a hacienda local, las que de conformidad con la legislación local no sean competencia de los Ayuntamientos y

26 En este sentido, para precisar el alcance de la LOMR, sostiene Lasagabaster que al hacer referencia el legislador orgánico «a aquellas que están previstas en la Constitución, lo que significa que las no previstas, así las que pudieran realizarse en el ámbito autonómico y que no estén previstas en la Constitución, no estarían sometidas a ese régimen jurídico”. Ibídem, pág. 67. 
aquellas otras que tengan un alcance supramunicipal. La autorización del Gobierno culminará este proceso. Cabe señalar que por parte del Gobierno se elaboró el Proyecto de Real Decreto regulador del procedimiento de autorización por el Gobierno de la Nación de las consultas populares municipa$\operatorname{les}^{27}$ que fue informado favorablemente por el Consejo de Estado, si bien su aprobación no prosperó ${ }^{28}$.

Pero aún cuando el legislador ha omitido en la LOMR referencia alguna a esta consulta por remisión a la legislación local, debemos destacar que diversas Comunidades Autónomas han regulado a través de normas autonómicas la celebración de referéndum locales, pese a la imprevisión del legislador orgánico sobre el tema. No obstante, podría tener justificación si se considera esta consulta como manifestación de participación directa diferenciada de los referéndum. Si bien hay que admitir la coherencia en la denominación de estas "Consultas populares" en los textos estatutarios y las normas autonómicas que los desarrollan, como antes se han indicado, dejaría abierta la vía para reflexionar sobre la relación entre referéndum y consulta popular.

Algunos Estatutos de Autonomía se han hecho eco de la competencia de "desarrollo legislativo del sistema de consultas populares" de ámbito municipal (Andalucía, Cataluña y Valencia), en otros sin embargo en el marco de la legislación básica del Estado se ha asumido la competencia de "desarrollo legislativo y la ejecución del sistema de consultas populares" (Asturias, Baleares, Castilla y León, Canarias, Extremadura, Murcia y La Rioja). Finalmente otras Comunidades que no contaban con una atribución estatutaria concreta con fundamento en la competencia sobre régimen local también podrían regular esta materia como ha sucedido en Navarra. Sin embargo, hasta las reformas estatutarias iniciadas en 2006 solo Andalucía (Ley 2/2001 de regulación de las consultas populares locales de Andalucía) y Navarra (Ley Foral 27/2002 de consultas populares de Navarra) habían elaborado una norma concreta para regular estas consultas en el ámbito local. En otras Comunidades en el marco de la legislación local han tenido acogida dichas consultas, como ha sucedido con el Decreto 294/1996 por el que se aprueba el Reglamento de Consultas Populares Municipales en aplicación de las previsiones relativas a la Ley 8/1987 municipal y de régimen local de Cataluña o la Ley 7/1999 de Administración local de Aragón (art. 157). En todo caso cabe recordar que el Decreto catalán que regula el referéndum local y el artículo

27 La fundamentación de este Real Decreto descansaría en el art. 149.1.18 CE en desarrollo del art. 71 de la LBRL.

28 La autorización para el referéndum revestirá forma de Acuerdo del Consejo de Ministros, a propuesta del Ministro de Administraciones Públicas (art. 1). Además se preveía que una vez cumplidos los trámites previstos en la legislación autonómica, el órgano competente de conformidad con dicha legislación o, de no haberse dictado la misma, el Alcalde que solicita la autorización de la consulta popular, remitiría el expediente al Ministerio de Administraciones Públicas para que procediese a la continuación del procedimiento (art. 2). Respecto del plazo máximo para resolver la solicitud de convocatoria sería de 3 meses, si bien transcurrido este plazo sin notificación del acuerdo del Consejo de Ministros, la solicitud se entendería estimada y se podría proceder a su convocatoria (art. 3). 
10.2 del Estatuto de Cataluña de 1979 indicaba que la Generalitat ha de remitir la solicitud municipal al Gobierno del Estado, a quien corresponde autorizar la consulta (art. 6.2). En el mismo sentido, el texto del Estatuto Andaluz de 1981 señalaba que "corresponde al Gobierno de la nación el acuerdo de autorización para la celebración de la consulta popular local» ${ }^{29}$.

\section{EL REFERÉNDUM EN EL ÁMBITO AUTONÓMICO}

El verdadero problema no resuelto por el legislador orgánico es el de si se contiene en la LOMR la enumeración exhaustiva de los procedimientos de referéndum o si son posibles otros desarrollos de mecanismos de participación directa fuera de lo previsto en ella. El origen de esta duda se encuentra en la dicción del artículo 149.1.32 CE: la "autorización para la convocatoria de consultas populares por vía de referéndum". Llegados a este punto quizá fuese adecuado realizar un breve balance de las consultas llevadas a cabo hasta el momento al objeto de clarificar el carácter, en su caso, exhaustivo de la LOMR. Recordemos que la regulación constitucional del referéndum consultivo no admite duda alguna en cuanto a la competencia para la autorización y convocatoria del mismo, pues solo el Presidente del Gobierno puede tomar la decisión, aunque precisa la autorización del Congreso de los Diputados y la convocatoria debe realizarse en Real Decreto acordado en el Consejo de Ministros. En efecto, el ejercicio de la competencia exclusiva del Presidente del Gobierno se ha concretado en la convocatoria de los referéndum sobre la permanencia de España en la OTAN así como sobre el proyecto de Tratado por el que se instituye una Constitución para Europa.

El tratamiento más amplio que se contiene en la LOMR es el relativo al conjunto de referéndum susceptibles de celebración en el ámbito autonómi$\mathrm{co}$, si bien hay que destacar que tampoco realiza la LOMR aportación alguna de carácter sustancial a la regulación de los referéndum de reforma estatutaria, limitándose a exigir el cumplimiento de los requisitos previamente establecidos en los respectivos Estatutos. Por tanto hemos de reparar en el referéndum como elemento constitutivo en el procedimiento de creación de las Comunidades Autónomas y en la aprobación y reforma estatutaria.

Únicamente en el procedimiento de acceso a la autonomía (art. 151 CE) se introdujo, como requisito imprescindible para la perfección del proceso, la celebración de consultas directas a la población afectada. Por tanto, el constituyente optó por recoger el referéndum como elemento constitutivo en el

29 Como ha señalado el Tribunal Supremo «la decisión del Consejo de Ministros de autorizar o denegar la convocatoria de una consulta popular municipal se configura en nuestro ordenamiento jurídico como un acto de control de que la solicitud se ajuste a los requisitos legalmente previstos de naturaleza procedimental". En este sentido la STS de 23 de septiembre de 2008 que contiene la declaración de nulidad del acuerdo del Consejo de Ministros que denegó la autorización para celebrar una consulta popular referida a la aprobación inicial del Plan General de ordenación urbanística de Almuñécar (Granada). 
proceso de creación de las Comunidades Autónomas a través del mecanismo regulado por el artículo 151 CE y omitió cualquier referencia al referéndum para el proceso de incorporación a la autonomía por la vía del art. $143 \mathrm{CE}$. Así los territorios que en el pasado hubieran plebiscitado "afirmativamente proyectos de Estatuto de Autonomía" quedaron exentos del referéndum de ratificación de la iniciativa autonómica. Curiosamente estamos en presencia del único referéndum en el que se ha fijado un quórum de participación y votación favorable siendo además en ambos casos muy elevado.

Respecto de los referéndum de constitución de la Comunidad Autónoma y de aprobación de los Estatutos de Autonomía, las convocatorias respectivas se realizaron por parte del Gobierno de la nación de conformidad con las previsiones constitucionales, aunque los referéndum de aprobación de los Estatutos de Autonomía presentaron alguna nota peculiar. Es significativo que la vía utilizada por el Gobierno para la ratificación popular de los Estatutos del País Vasco y de Cataluña vulnerara la reserva material de Ley Orgánica tanto respecto a las condiciones y procedimientos (art. $92 \mathrm{CE}$ ), como a los términos y forma (art. $151 \mathrm{CE}$ ) en que se debía producir la consulta. Además permitió la puesta en vigor de una norma preconstitucional derogada ${ }^{30}$.

La aprobación de la LOMR y su entrada en vigor creó un marco normativo al que se habían de ajustar los referéndum para la aprobación de los Estatutos de Autonomía de aquellas Comunidades Autónomas que hubiesen optado por el procedimiento establecido en el artículo $151 \mathrm{CE}^{31}$.

En el caso de los referéndum de reforma de los Estatutos de Autonomía la LOMR efectúa una remisión a los trámites previstos en los Estatutos de Autonomía para su modificación (art. 152.2 CE) limitándose a indicar que el referéndum debe ser convocado en el plazo de seis meses desde el cumplimiento de dichos trámites sin mayor precisión. Cabe decir que respecto del órgano convocante, podemos constatar un planteamiento teórico diverso en los Estatutos de Autonomía ya que la relevancia de la reforma estatutaria justifica su tratamiento diferenciado, si bien el referente último de este procedimiento viene determinado por los artículos. 147.3 y $152.2 \mathrm{CE}$. El primero de ellos respecto al ámbito global en el que ha de desenvolverse y transcurrir el procedimiento de reforma estatutaria. Así en el art. 152.2 CE se concreta cuál es la regulación específica que debe tenerse en cuenta a la hora de proceder a la reforma de un Estatuto de Autonomía que precisó para su aprobación previa consulta popular. De tal modo que si el art. 147.3 CE es de aplicación a todos los Estatutos de Autonomía para su reforma, el art. 152.2 CE sólo lo

30 La convocatoria de referéndum para la aprobación del Estatuto del País Vasco se efectuó por Real Decreto-ley 13/1979, la convocatoria de referéndum para la aprobación del Estatuto de Cataluña se realizó por Real Decreto-ley 14/1979. En ambos casos la norma convocante contenía una remisión al Real Decreto 2120/1978 sobre normas para la celebración de consultas directas a la nación y tuvieron lugar el 25 de octubre de 1979.

31 El referéndum de aprobación del Estatuto de Autonomía de Galicia se celebró el 21 de diciembre de 1980, el 20 de octubre de 1981 tuvo lugar el referéndum de aprobación del Estatuto de Andalucía. 
es para las Comunidades Autónomas constituidas a través del procedimiento establecido en el art. 151 y la Disposición Transitoria 2. ${ }^{a}$ CE. Por tanto la celebración necesariamente de una consulta popular es una exigencia constitucional derivada del art. 152.2 CE. Los cuatro Estatutos de Autonomía ratificados por referéndum contemplan dos procedimientos diferentes para su reforma atendiendo al objeto de la misma: según se altere o no la organización de los poderes de la Comunidad y afecte a sus relaciones con el Estado.

Pero como hemos adelantado las previsiones estatutarias tampoco son idénticas. De este modo, para la reforma estatutaria que afecte a las relaciones entre la Comunidad Autónoma y el Estado, el gobierno Vasco "podrá ser facultado, por delegación expresa del Estado, para convocar los referéndum" (art. 46.2), mientras que en los Estatutos Catalán y Gallego la Ley Orgánica que contenga la aprobación de la reforma por las Cortes Generales "incluirá la autorización del Estado para que" la Comunidad convoque el referéndum. Por su parte el Estatuto Andaluz de 1981 indicaba que la Ley Orgánica "que apruebe la reforma del Estatuto establecerá el plazo dentro del cual el gobierno de la nación deberá autorizar la convocatoria del referéndum" (art. 74.3). En cuanto al otro procedimiento de reforma estatutario, coincidían los cuatro Estatutos en establecer que el electorado será consultado por medio de referéndum "debidamente autorizado" por el Estado.

Recordemos que una vez aprobado el proyecto de reforma del Estatuto de Cataluña por las Cortes Generales se convocó, de conformidad con lo previsto en el art. 56 del Estatuto de 1979, por Decreto 170/2006 de la Comunidad Autónoma de Cataluña referéndum positivo de las personas electoras de Cataluña ${ }^{32}$. El Estatuto de 2006 reproduce la necesaria consulta a los ciudadanos de la reforma estatuaria aprobada por las Cortes Generales mediante una Ley Orgánica que incluirá la autorización del Estado para que la Generalitat convoque dicha consulta (arts. 222 y 223.1.i).

En cuanto a la otra reforma estatutaria operada sobre un Estatuto aprobado en referéndum hemos de señalar que tras la aprobación por las Cortes Generales del proyecto de reforma del Estatuto de Autonomía de Andalucía, el Consejo de Ministros en su reunión de 22 de diciembre de 2006 y a propuesta del Presidente del Gobierno, adoptó el acuerdo por el que se autorizó la convocatoria de referéndum ${ }^{33}$.

Por lo que respecta a otras modalidades de referéndum en el ámbito autonómico: como el procedimiento para la supresión del art. 17.6.b) del Estatuto de Autonomía del País Vasco (art. 47.3 EAPV), o sobre la alteración de los límites geográficos (art. 8 EAPV $^{34}$ ) y la consulta prevista en aplicación

32 La consulta tuvo lugar el 18 de junio de 2006.

33 La consulta de aprobación del Estatuto de Autonomía de Andalucía tuvo lugar el 18 de febrero de 2007.

34 La Puebla de Arganzón y el Condado de Treviño que, respectivamente el 17 de octubre y el 26 de enero de 1980 adoptaron los correspondientes acuerdos para su integración en la provincia de Álava y la CCAA del País Vasco. Una vez ratificados los acuerdos por los municipios, solicitado y emitido el informe del Gobierno Vasco y sin que ni la Diputación Provincial de Bur- 
de la Disposición Transitoria 4. ${ }^{\mathrm{a}} \mathrm{CE}$, no podemos ocuparnos aquí. En todo caso, cabe señalar la novedad que supone la incorporación del referéndum al proceso de reforma introducido en la última reforma del Estatuto de Autonomía de la Comunidad Autónoma de Valencia (art. 81.5) que contrasta también con las previsiones contenidas en la LOMR y, sin embargo, no ha sido objeto de ninguna impugnación.

De este breve análisis de la experiencia referendaria parece deducirse que no siempre las previsiones legales se han cumplido, incluso cabría afirmar que al margen de lo regulado en la LOMR se han llevado a cabo algunas consultas o se han incorporado por vía legislativa al Estatuto o a la regulación básica estatal o autonómica otros referéndum no recogidos previamente en la LOMR.

Una vez constatada esta realidad y puesto que la LOMR no ha determinado si tienen cabida bajo el art. 149.1.32 CE los referéndum autonómicos de carácter facultativo, entendemos que en principio nada debe impedir que en el ámbito de las competencias que le reconozca el Estatuto de Autonomía correspondiente, se pudiesen llevar a cabo con carácter consultivo dentro del territorio de la Comunidad Autónoma consultas populares. La reforma del Estatuto de Valencia que ha permitido la incorporación de un nuevo tipo de consulta, ya que el Presidente de la Generalitat podrá proponer la celebración de consultas populares "sobre cuestiones de interés general en materias autonómicas o locales" en el marco de la legislación del Estado (art. 28.5 EAV), vendría a corroborar la opinión aquí manifestada. Sería conveniente no obstante que en una futura reforma de la LOMR se incorporara expresamente el referéndum consultivo autonómico con especificaciones procedimentales generales, sin perjuicio de la remisión expresa al ámbito estatutario para su desarrollo.

\section{LAS PERSPECTIVAS QUE ABREN LAS NUEVAS REGULACIONES ESTATUTARIAS}

La concurrencia de un lado del reconocimiento del derecho de los ciudadanos a promover la convocatoria de consultas populares en los Estatutos de Cataluña (art. 29.6), Andalucía (art. 30), Baleares (art. 15, c) y Castilla y León (art. 11.5) y la posibilidad, de otra parte, de poner en marcha un refe-

gos ni la CCAA de Castilla y León se manifestasen al respecto, se produjo la aprobación por Ley Orgánica 4/1983 del Estatuto de esta Comunidad con la inclusión en éste de un procedimiento para la segregación de enclaves de la misma ubicados en el interior del territorio de otra Comunidad (Disposición Transitoria 7. ${ }^{a}$ ). En la Sentencia que pone fin a los recursos de inconstitucionalidad acumulados en su día, se concluye la constitucionalidad de la disposición Transitoria $7 .{ }^{\mathrm{a}}$ del Estatuto de Castilla y León por entender que no existe colisión alguna entre la regulación de un procedimiento de incorporación al País Vasco contenido en el art. 8 de su Estatuto y la regulación de la posible segregación de su territorio de municipios de la CCAA de Castilla y León (STC 99/1986). 
réndum consultivo autonómico, exige determinar la compatibilidad entre ambos términos de esta proposición.

Debemos recordar que por cuanto respecta al referéndum consultivo nos encontramos ante una consulta facultativa, de carácter propositivo, de iniciativa gubernamental exclusivamente contemplada en el artículo 92 CE para propiciar la participación ciudadana en torno a decisiones de especial trascendencia y circunscrita su propuesta al Presidente del Gobierno. Las decisiones políticas de especial trascendencia cabe señalar que nos plantea la dificultad que supone para el intérprete dilucidar el sentido concreto de estos términos. Se trata además de un concepto sin control externo que evidencia el deseo de dejar en el convocante un margen de libertad de extraordinaria amplitud y sólo cabe pensar que el objeto de la consulta debe permanecer dentro del ámbito de competencias del convocante del mismo. En la regulación del referéndum consultivo en la LOMR sólo se reproducen los términos del art. 921 y 2 CE. En ningún momento se plantea concreción alguna respecto a cuál es el ámbito de aplicación del referéndum, así como las mayorías necesarias para producir un resultado vinculante.

Ahora bien, el debate se podría centrar en la viabilidad de este referéndum consultivo en el ámbito autonómico, aun cuando no estaría comprendido en la LOMR. Recuérdese que no están reconocidos expresamente en la Constitución ni en la LOMR los referéndum previstos en el Estatuto de Autonomía del País Vasco en el caso de integración de territorios o municipios o el relativo al procedimiento para la supresión del art. 17.6.b de dicho Estatuto, y sin embargo ello no conlleva duda de inconstitucionalidad. Como queda indicado, la no previsión de las consultas locales no invalidan su regulación autonómica. Entendemos en el mismo sentido que el derecho fundamental a la participación directa de los ciudadanos en los asuntos públicos no queda agotado por sus manifestaciones recogidas en la LOMR.

Este razonamiento nos lleva a apostar por la posibilidad de nuevas formas de referéndum en el ámbito autonómico siempre que no se cuestione la competencia exclusiva del Estado para la autorización de la convocatoria de consultas populares por vía de referéndum, si ha tenido reconocimiento estatutario y que se complementaría con el derecho "estatutario" reconocido a los ciudadanos para solicitar su convocatoria. Por tanto, el reconocimiento estatutario de la competencia exclusiva en la materia, así como el mandato contenido en el mismo para que el legislador autonómico desarrolle las condiciones de realización de la consulta y el ejercicio del derecho reconocido a los ciudadanos de iniciativa en materia de consultas populares, permitiría cumplir los requisitos derivados de la reciente jurisprudencia constitucional siempre que la autorización correspondiese al Estado. La nueva redacción de los Estatutos de Autonomía de Cataluña y Andalucía podrían dar cabida a este tipo de consulta con un desarrollo legislativo previo y manteniendo en todo caso la necesidad de obtener la autorización del Estado para poder llevar a cabo su convocatoria. 
La cuestión ausente de consideración hasta este momento en el análisis que estamos desarrollando es la relativa a la pertinencia, y adecuada caracterización de la autorización estatal de la convocatoria de referéndum. Nos hemos de hacer eco aquí de la doctrina del Consejo de Estado sobre esta materia. Por ello queremos recordar, en primer lugar, el Dictamen del Consejo de Estado 943/94, de 9 de junio de 1994 en el que se analizaba la naturaleza jurídica de la autorización del Gobierno de la nación prevista en el artículo 71 de la LBRL. En esta asunto el Consejo entendía que "la referida autorización es un acto administrativo de control sobre la conformidad de la solicitud de someter la cuestión a una consulta popular municipal con los requisitos legalmente previstos al efecto; ha de ser caracterizada, por tanto, como un típico acto administrativo y no, por el contrario, como una actuación del Gobierno no sujeta al derecho administrativo". La segunda cuestión que se planteaba en el citado Dictamen era la relativa a si la solicitud que precede a la autorización encaja pacíficamente en las «solicitudes formuladas por los interesados" que se recoge en el art. 43.2 de la Ley 30/1992 en la que el Consejo entendía que "la falta de resolución expresa y el principio de silencio administrativo positivo son aplicables a la autorización que el art. 71 de la Ley 7/1985 atribuye al Gobierno de la Nación".

En segundo lugar, el Dictamen 1070/2001 relativo al Proyecto de Real Decreto regulador del procedimiento de autorización por el Gobierno de la Nación de las consultas populares municipales reitera la doctrina ya señalada en el Dictamen 943/1994 "la configuración de la autorización como un acto administrativo de control de que la solicitud de someter la cuestión a una consulta popular municipal se ajusta a los requisitos legalmente previstos al efecto (...) en el que recordaba que tales requisitos eran de una doble índole; de naturaleza procedimental y expresión del adecuado equilibrio entre el principio representativo y el principio de participación directa, puesto que se exige que la consulta popular municipal sea solicitada por los respectivos Alcaldes, previo acuerdo por mayoría absoluta del Pleno de la correspondiente Corporación Municipal; y de naturaleza material, consistente en admitir únicamente consultas relativas a asuntos que reúnan simultáneamente las notas de ser de la competencia propia municipal, de carácter local y de especial relevancia para los intereses de los vecinos, excluyéndose, en todo caso, los asuntos relativos a la hacienda local". Otra cuestión resuelta en aquel Dictamen era la relativa a la caracterización de los informes previos de la Delegación del Gobierno en la Comunidad Autónoma donde radique el municipio cuyo alcalde solicite la autorización, del Ministerio competente por razón de la materia y de la Comunidad Autónoma correspondiente ${ }^{35}$. Entendía el

35 La mayoría de las disposiciones autonómicas prevén la remisión de la solicitud al Gobierno de la nación junto con su informe (art. 10.3 de la ley 2/2001, de Andalucía) que en algunos casos tendrá como objeto la conveniencia de efectuar la consulta, de conformidad con el interés general de la Comunidad Autónoma (arts. 144.4 b de la Ley 8/1987, de Cataluña, y 257.3 b de la Ley 5/1997, de 22 de junio de Galicia) o a la vista del interés general (art. 157.3 b de la Ley 7/1999, de 9 de abril de Aragón). 
Consejo de Estado que "no son determinantes del contenido de la resolución de autorización o denegación - que corresponde en exclusiva al Gobierno de la Nación y en tal sentido no se preve la suspensión del procedimiento para su evacuación (art. 42.5 c de la Ley 30/1992), ni se impide la continuación del procediendo ante su omisión en plazo (art. 83 de Ley 30/92)".

Una posible opción para no vulnerar la autorización estatal de conformidad con el artículo 149.1.32 CE hubiera sido la transferencia de la competencia del Estado a la Generalidad en esta materia de autorización de convocatorias de referéndum a través de la correspondiente Ley Orgánica de transferencia de competencias del artículo 150.2 CE, aunque cabe recordar que no ha prosperado en otras ocasiones que se ha formulado. En efecto, esta reivindicación ya aparecía en la Propuesta de reforma estatutaria aprobada por el Parlamento de Cataluña que además también se incluyó inicialmente en la Propuesta de reforma del Estatuto de Andalucía.

Una vez analizadas las previsiones relativas a la autorización de la convocatoria de referéndum solo nos resta afirmar nuestro convencimiento de la viabilidad de la competencia exclusiva de las Comunidades Autónomas de Cataluña y Andalucía en materia de referéndum consultivos autonómicos. En la medida en que el legislador autonómico desarrolle las previsiones estatutarias respetando los anteriores criterios no habría nada que objetar a los referéndum autonómicos con la consideración del cuerpo electoral autonómico, en el ejercicio del derecho fundamental de participación política, siempre que el asunto de trascendencia sujeto a consulta afectara a las competencias exclusivas de las Comunidades Autónomas y se llevara a cabo la autorización para la consulta de conformidad con la Constitución y la LOMR.

En suma aplicando la doctrina del Tribunal Constitucional estaríamos ante la asunción competencial en los Estatutos de Cataluña y Andalucía de las consultas populares cuya convocatoria requiere autorización reservada al Estado, cuyo sujeto consultado se identifica con el censo autonómico, con sus correspondientes garantías, sobre objeto de competencia autonómica. Sí se podría cuestionar su alcance, que permitiría limitarlo a cuestiones de autoorganización en sentido estricto, sobre lo que no cabe ninguna duda, o bien un entendimiento más amplio de "indirizzo político".

Concluimos pues esta reflexión apuntando, al objeto de caracterizar los instrumentos de participación directa recogidos en los nuevos Estatutos de Autonomía, que éstos permitirían el desarrollo legislativo por las Comunidades Autónomas y su convocatoria por el ejecutivo autonómico de las consultas por vía de referéndum siempre que cumpliese los requisitos ya señalados: autorización del gobierno de la nación, sobre materia de competencia de la Comunidad Autónoma y como destinatarios a todo el censo electoral de la Comunidad. La concreción de los aspectos procedimentales, de administración electoral, número de peticionarios o participación, etc., serían objeto de regulación en la norma autonómica correspondiente. La discusión puede alcanzar al carácter supletorio de la legislación electoral autonómica o a la LOREG, pero en todo caso no encontramos razones de fondo para negar esta 
posibilidad de instrumentar desde el principio democrático la institucionalización en el ámbito autonómico de mecanismos de participación directa, orientados a llevar a cabo consultas a los ciudadanos de la Comunidad Autónoma sobre temas de su competencia e interés. Esta hipótesis no invalidaría, ni supliría, otras opciones contempladas en los Estatutos como encuestas de opinión, audiencias públicas o foros de participación.

TITLE: The exclusive competence of Autonomous Regions to bold referendums

Aвstract: Among new legal provisions of recent Catalonian and Andalusian Statutes, there is the possibility that both Regions can call to referendum their populations. So Catalonian Government on March 31th 2009 approved a Bill on the subject. This contribution focuses on several issues concerning this new competence. Also Constitutional Court has ruled the topic in Sentences $247 / 2007$ and 103/2008 which are an important framework to face the constitutionality of Regional referendums in Spain.

Resumen: Los nuevos Estatutos de Autonomía de Cataluña y Andalucía ban incorporado la competencia para convocar referéndum en el ámbito autonómico. El 31 de marzo de 2009 el Gobierno de Cataluña ha aprobado un proyecto de ley para su tramitación parlamentaria que desarrolla la previsión estatutaria relativa a la convocatoria y celebración de referéndum. Las recientes sentencias del Tribunal Constitucional (SSTC 247/2007 y 103/2008) constituyen un material imprescindible para reflexionar sobre la viabilidad de las consultas populares en el ámbito autonómico.

Key worDs: Referendum. Regions. Statutes of Autonomy. Distribution of competences.

Palabras Clave: Referéndum. Comunidades Autónomas. Distribución de competencias. 